Table 1

Individual Daily Frequencies of Choosing the $30 \%$ Stimulus (Daily Maximum $=30$ )

\begin{tabular}{|c|c|c|c|c|c|c|c|c|c|c|c|c|c|c|c|c|c|c|c|c|c|c|}
\hline \multirow[b]{2}{*}{$\mathbf{S}$} & \multirow[b]{2}{*}{ FR } & \multirow{2}{*}{$\begin{array}{c}30 \% \\
\text { Color }\end{array}$} & \multirow{2}{*}{$\begin{array}{c}\text { TO } \\
\text { Dura- } \\
\text { tion }\end{array}$} & \multicolumn{19}{|c|}{ Days } \\
\hline & & & & 1 & 2 & 3 & 4 & 5 & 6 & 7 & 8 & 9 & 10 & 11 & 12 & 13 & 14 & 15 & 16 & 17 & 18 & 19 \\
\hline 1 & 10 & $\mathbf{G}$ & 2 & 16 & 14 & 11 & 16 & 13 & 12 & 13 & 14 & 13 & 19 & 16 & 20 & 18 & 17 & 14 & 29 & 28 & 28 & \\
\hline 2 & 10 & $\mathbf{R}$ & 2 & 15 & 15 & 20 & 19 & 14 & 19 & 18 & 17 & 20 & 19 & 19 & 19 & 19 & 29 & 21 & 22 & 29 & 28 & 30 \\
\hline 3 & 10 & $\mathbf{G}$ & 5 & 12 & 17 & 16 & 19 & 16 & 20 & 15 & 23 & 20 & 21 & 21 & 23 & 18 & 24 & 24 & 24 & 28 & 28 & 29 \\
\hline 4 & 10 & $\mathbf{R}$ & 5 & 15 & 14 & 17 & 16 & 16 & 18 & 19 & 20 & 19 & 28 & 23 & 22 & 29 & 26 & 29 & 30 & 30 & & \\
\hline 5 & 20 & $\mathbf{R}$ & 2 & 18 & 16 & 19 & 23 & 26 & 27 & 27 & 22 & 18 & 29 & 26 & 21 & 24 & 28 & 28 & 28 & & & \\
\hline 6 & 20 & $\mathbf{G}$ & 2 & 12 & 14 & 17 & 10 & 5 & 6 & 19 & 20 & 24 & 24 & 24 & 30 & 30 & 28 & & & & & \\
\hline 7 & 20 & $\mathbf{R}$ & 5 & 15 & 13 & 16 & 20 & 26 & 20 & 21 & 18 & 20 & 16 & 14 & 19 & 27 & 28 & 28 & 28 & & & \\
\hline 8 & 20 & $\mathbf{G}$ & 5 & 12 & 14 & 15 & 17 & 19 & 16 & 16 & 18 & 17 & 18 & 19 & 24 & 20 & 28 & 29 & 29 & & & \\
\hline
\end{tabular}

lacked any initial color preference. More importantly, inspection of Table 1 reveals that all Ss gradually developed a preference for the $30 \%$ stimulus until they were choosing it on nearly every trial. This result indicates that pigeons, given extended acquisition, will maximize the nonoccurrence of TO in a probability-learning situation while responding for food reinforcement. The importance of extended acquisition in probability-learning studies has been noted elsewhere (Shimp, 1966; Topping \& Parker, in press), and the present findings suggest that previous probability-learning experiments with shock reinforcement might have resulted in complete maximizing had more training been given.

A one-way ANOVA used to assess the effect of TO duration on the rate of reaching the maximizing criterion revealed that this main effect was not significant $(F<1)$. This result is inconsistent with previous research (cf. Kaufman \& Baron, 1968), which has found that the effectiveness of $\mathrm{TO}$ is an increasing function of its duration; however, the lack of a differential effect in the present study was probably due to the small difference between the durations used.

A similar analysis indicated that the FR requirement had a significant differential effect $(F=15.76, d f=1 / 6, p<.01)$, with the larger $F R$ value resulting in more rapid maximizing. Thompson (1964) observed that rats show an increasing preference for TO as the FR requirement increases. $\mathrm{He}$ attributed this finding to the increasing aversiveness of the FR schedule as the response requirement became more and more strained. The fact that all Ss maximized the nonoccurrence of TO in the present study suggests that FR values of 10 and 20 are not particularly aversive, but that TO is aversive. Thus, there appears to be some type of curvilinear relationship between the FR requirement and preference for TO. Investigations in the Es' laboratory have been planned to investigate the nature of this relationship as well as the possible interaction of FR requirement and percentage and duration of $\mathrm{TO}$.

\section{REFERENCES}

BAER, D. M. Escape and avoidance responses of preschool children to two schedules of reinforcement withdrawal. Journal of the Experimental Analysis of Behavior, 1960, 3, 155-159.

BARON, A., \& KAUFMAN, A. Time-out punishment: Preexposure to time-out and opportunity to respond during time-out. Joumal of Comparative \& Physiological Psychology, 1969, 67, 479-485.

COLE, M., BFLENKY, G. L., BOUCHER, R. C. FERNANDEZ, R. N., \& MYERS, D. L. Probability learning to escape from shock. Psychonomic Science, 1965, 3, 127-128.

KAUFMAN, A., \& BARON, A. Suppression of behavior by time-out punishment when suppression results in loss of positive reinforcement. Journal of the Experimental Analysis of Behavior, 1968, 11, 595-607.

LEITENBERG, $H$. Is time-out from positive reinforcement an aversive event? A review of the experimental evidence. Psychological
Bulletin, 1965, 64, 428-441.

SHIMP, C. P. Probabilistically reinforced choice behavior in pigeons. Journal of the Experimental Analysis of Behavior, 1966, 9, $443-455$.

THOMAS, J. R. Discriminated time-out avoidance in pigeons. Journal of the Experimental Analysis of Behavior, 1965, 8, 328-338.

THOMPSON, D. M. Escape from $S^{D}$ associated with fixed-ratio reinforcement. Journal of the Experimental Analysis of Behavior, 1964, 7 1.8 .

TOPPING, J. S. \& PARKER, B. K. Constant and variable delay of reinforcement effects on probability learning by pigeons. Journal of Comparative \& Physiological Psychology, in press.

YOUNG, F. W., \& PEEKE, H. V. S. Probability learning in the goldfish: I. Aversive reinforcement. Psychonomic Science, 1966, 4, 373-374.

\title{
Retention of habituation of exploratory behavior
}

\section{RICHARD M. O'BRIEN and CHARLES D. CORMAN, West Virginia University, Morgantown, W. Va. 26506}

Two groups of rats were tested in an open field. One group was exposed to a novel stimulus change with the field. After 90 days, animals were retested with both groups experiencing the stimulus change. The group having had prior exposure showed retention of the habituation of exploratory behavior.

In studying open-field activity in normal rats as compared to Ss with septal and amygdaloid preparations, Corman, Meyer, \& Meyer (1967) used a procedure that seemed especially suited to investigating exploratory behavior. Using an open field divided into equal squares, these authors measured locomotion, number of squares traversed, time in center (time spent in squares not bordering on the walls of the field), and latency in leaving the startbox, both before and after the insertion of a novel stimulus in the center of the field.

Extending this work specifically to the investigation of exploratory behavior, Corman \& Shafer (1968) demonstrated that the introduction of a white square into the center of a homogeneous black field elicited approach behaviors that habituated with repeated testing. The present study was undertaken to examine the effects of interspersing a substantial period of nonexposure to the test situation on the habituation of tendencies to approach the white square.

\section{SUBJECTS AND APPARATUS}

The Ss were 18 male hooded rats, approximately 30 days old at the beginning of gentling. Food and water were continually available to the Ss except during the experimental sessions. Ss were ear-punched for identification.

The apparatus, as described by Corman \& Shafer (1968), was a 45 -in. square open 
field, enclosed by grey walls, 24 in. high. The floor consisted of 9-in. squares of black linoleum tile. The novel stimulus was an identical white linoleum tile. A two-sided startbox, $9 \times 9 \times 12$ in., was placed in a corner of the field so that the walls of the field completed the box. A hinged top permitted insertion of the animal into the startbox, while a long handle permitted the lifting of the box from the field at the beginning of each trial. The field was illuminated by a $15-W$ fluorescent light suspended $20 \mathrm{in}$. above the center of the field. The $E$ sat adjacent to the field in the otherwise darkened room. Two buttons of a hand-held switchbox were used to record time in center and locomotion on a Hunter Klockounter and a 6-V Mercury Counter, respectively. A stopwatch was used to record latencies.

\section{PROCEDURE}

Prior to the beginning of the experiment, the animals were gentled for 12 days. Experimental trials began by placing the $S$ in the startbox. After $30 \mathrm{sec}$, the startbox was gently lifted from the apparatus. The animal was then observed in the open field for $3 \mathrm{~min}$. Four behavioral measures were taken: latency in leaving the starting square, a locomotion score (number of squares entered with one or more paws during the test period), a time-in-center score (total time, in seconds, in contact with squares not adjacent to the wails of the field), and a bolus count. Each animal received one trial per day. After each trial, the field was mopped and allowed to dry before another $S$ was tested.

The Ss were tested in two 12-trial sessions separated by an interval of 90 days. For the first six trials of Session 1, all Ss were exposed to the homogeneous black field. At this point, the Ss were ranked and matched on the basis of their locomotion scores. For the next six trials, the white square was introduced in the center of the field for Group 1, the early-experience group, while Group 2 continued to be exposed to the homogeneous black field. Thus, the first session consisted of 12 trials run over 12 days in which Group 2 saw only the homogeneous field, while Group 1 was being exposed to the white square on the last six trials.

A period of 90 days was then allowed to pass before the Ss were again gentled for 12 days and run for another 12-trial session. As before, both groups saw only the homogeneous field for the first six trials; however, on Day 7, the white square was instituted for both groups. This procedure was identical to the first session for Group 1 but marked Group 2's first exposure to the white square.

\section{RESULTS AND DISCUSSION}

Neither latency nor bolus count showed any relation to the experimental manipulations. The former showed only inter-S variability, while the latter decreased to zero after four or five sessions in all but two of the Ss.

Time in center ( $t-i-c)$ and locomotion scores (Loc) were analyzed by ANOVA according to Steel \& Torrie (1960) for a complete-block design. The data were analyzed in terms of matched blocks, days, treatment, Days by Treatment interaction, and Days by Blocks interaction.

The first 12 trials were basically a replication of Corman \& Shafer (1968). The "wall-hugging" tendency mentioned above could be seen in the animals' performance over the first six trials. The proportion of each trial spent in squares not adjacent to the walls of the field was much less than the relative area these squares occupy. Further, the slight, but significant, increase in $t-i-c$ observed in the earlier study's premanipulation trials was replicated in the current experiment.

On Trials 7 through 12 , a significant $(\mathrm{F}=3.522, \mathrm{df}=5 / 40, \mathrm{p}<.01)$ increase in locomotion over days occurred. The days by treatment for locomotion was also significant $(F=3.253, \mathrm{df}=5 / 40, \mathrm{p}<.05)$.

Mean $t-i-c$ scores for Session 1 are shown in Fig. 1. Analysis of the t-i-c data for the last six trials of Session 1 revealed a significant days effect $(F=4.597$, df $=5 / 40, p<.01$ ), treatment effect $(F=9.660, d f=1 / 8, p<.05)$, and Days by Treatment $(\mathrm{F}=3.173, \mathrm{df}=5 / 40, \mathrm{p}<.05)$. The data of Session 1 demonstrated that introduction of a novel stimulus elicits approach to the area of stimulus change with the open field and increased locomotor activity within the field.

The significant Days by Treatment effect should also be considered in connection with the significant days effect of decreasing $t-i-c$ over the last six trials. This shows that, on these trials, the great increase in $t-i-c$ that occurred in response to the introduction of the novel stimulus slowly dissipated to the point where, on

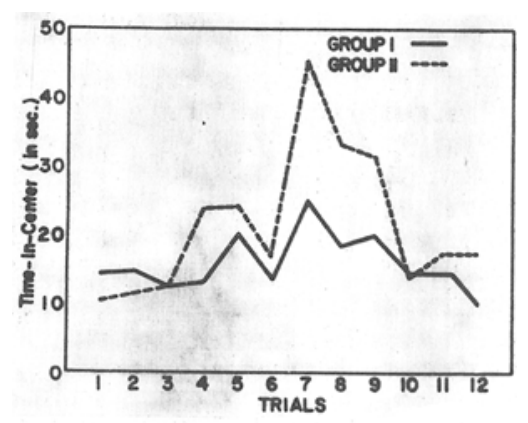

Fig. 1. Mean time in center (Session 1).

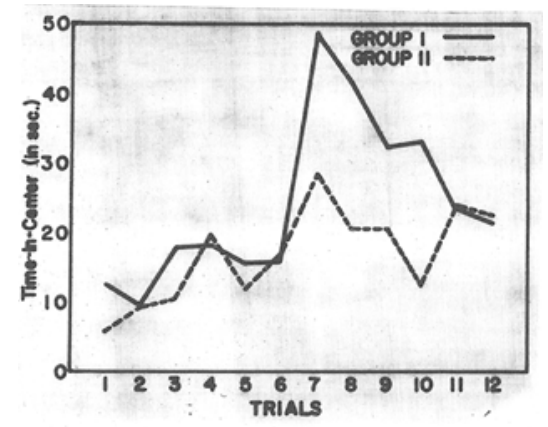

Fig. 2. Mean time in center (Session 2).

the last two trials, there was essentially no difference in $t-i-c$ between the two groups. Clearly, the approach behavior elicited by the novel stimulus had habituated by the fifth exposure.

Mean $t$-i-c scores for the 12 trials of Session 2 are shown in Fig. 2. On Trials 1 through 6 of Session 2, there were no significant group differences in the locomotion scores or in $t-i-c$. There was significant increase in $t-i-c$ over days $(F=3.364$, df $=5 / 40, p<.05)$ for all $\mathrm{Ss}$ over these six trials.

The introduction of the white square on Trials 7 through 12 of Session 2 produced divergence in the locomotor performance of the two groups. The greatest activity for both groups occurred on Trial 7. The decrease in locomotion over days from the high point at Day 7 to Day 12 was significant $(F=9.24, \mathrm{df}=5 / 40, \mathrm{p}<.01)$; however, group differences were evident on the Days by Group interaction $(F=1.744$, df $=40 / 40, p<.05$ ).

Time-in-center effects over the last six trials were significant for treatment $(\mathrm{F}=14.90, \quad \mathrm{df}=1 / 8, \quad \mathrm{p}<.01), \quad$ blocks $(F=4.228, \quad$ df $=8 / 8, \quad p<.05)$, days $(F=21.147$, df $=5 / 40, p<.01)$, and Days by Treatment $(F=3.981, \mathrm{df}=5 / 40$, $\mathrm{p}<.01$ ).

It will be recalled that Group 1 habituated to the novel stimulus over the six-trial exposure of Session 1. The significant difference between groups on Session 2 and the failure to find $a$ significant increase in $t-i-c$ for Group 1 when the white square was reintroduced indicates that prolonged absence from the experimental situation failed to eliminate the effects of prior habituation.

\section{REFERENCES}

CORMAN, C. D., MEYER, P. M., \& MEYER, D. $R$. Open field activity and exploration in rats with septal and amygdaloid lesions. Brain Research, 1967, 5, 469-476.

CORMAN, C. D., \& SHAFER, J. N. Open-field activity and exploratory behavior. Psychonomic Science, 1968, 13, 55-56.

STEEL, R. G. C., \& TORRIE, J. H. Principles and procedures of statistics. New York: McGraw-Hill, 1960. 